\title{
Representações da violência institucional em Infância dos Mortos, de José Louzeiro
}

\section{Eloísa Porto C. Allevato Braem ${ }^{1}$ Saron do Amaral Gomes ${ }^{2}$}

\begin{abstract}
Resumo: $O$ presente artigo aborda algumas representações da violência, especialmente em seu caráter institucional, contra crianças e jovens, no romance-reportagem de José Louzeiro, Infância dos Mortos (1977), estabelecendo diálogos com a História e com outras áreas do conhecimento que estudam o tema, como o Direito. Entre os trabalhos cotejados neste artigo estão os de André Gustavo de Paula Eduardo (2013), Elio Gaspari (2002), Marcos Napolitano (2011), Maria Cecília Minayo (2009), Márcio Rogério de Oliveira (2008), Vanessa Chiari Gonçalves (2013) e Michel Foucault (1984, 1987). Assumindo que a literatura está intrinsecamente ligada a fenômenos sociais, pretende-se apurar de que maneira a violência institucional é representada no romance-reportagem, qual é o seu delineamento conceitual, bem como seus desdobramentos e efeitos nos mecanismos de controle social na obra de Louzeiro.
\end{abstract}

Palavras-chave: Violência institucional; Infância dos Mortos; José Louzeiro.

\section{Representaciones de violencia institucional en Infância dos mortos, de José Louzeiro}

Resumen: Este artículo aborda algunas representaciones de violencia, en su carácter institucional, contra los niños y los jóvenes, en el romance-reportaje de José Louzeiro, estableciendo diálogos con la historia y otras áreas de conocimiento que estudian el tema, como Derecho. Entre los trabajos compilados en este artículo están los de André Gustavo de Paula Eduardo (2013), Elio Gaspari (2002), Marcos Napolitano (2011), Maria Cecilia Minayo (2009), Márcio Rogério de Oliveira (2008), Vanessa Chiari Gonçalves (2013) y Michel Foucault $(1984,1987)$. Suponiendo que la literatura está intrínsecamente vinculada a los fenómenos sociales, su objetivo es investigar cómo se representa la

\footnotetext{
${ }^{1}$ Eloísa Porto Corrêa Allevato Braem. Doutora em Letras Vernáculas (Literatura Portuguesa) pela Universidade Federal do Rio de Janeiro, professora Adjunta na Universidade do Estado do Rio de Janeiro, Brasil. E-mail: eloisaporto@gmail.com - https://orcid.org/0000-0001-5356-3059

${ }^{2}$ Saron do Amaral Gomes. Graduado em Letras/Literaturas pela Faculdade de Formação de Professores da Universidade do Estado do Rio de Janeiro (UERJ-FFP) E-mail: saron.do.valle@gmail.com - https://orcid.org/0000-0002-5710-8309
}

Este trabalho é um dos produtos da pesquisa de IC UERJ, coordenada pela Prof. a Dra. Eloisa Porto C. Allevato Braem, intitulada: O Direito na Literatura e no Cinema: um estudo sobre Infância dos Mortos, de José Louzeiro, e Pixote, a lei do mais fraco, dirigido por Hector Babenco. 
violencia institucional en el romance-reportaje, cuál es su esquema conceptual, así como sus consecuencias y efectos sobre los mecanismos de control social en el trabajo de José Louzeiro.

Palabras clave: Violencia institucional; Infância dos Mortos; José Louzeiro

Representations of institutional violence in Infância dos mortos, by José Louzeiro

\begin{abstract}
This article discusses some representations of violence, especially in its institutional character, against children and youth, in José Louzeiro's novel-reportage: Infância dos Mortos (1977), establishing dialogues with history and other areas of knowledge that study the theme, such the law. Among the collated works in this article are those of André Gustavo de Paula Eduardo (2013), Elio Gaspari (2002), Marcos Napolitano (2011), Maria Cecilia Minayo (2009), Márcio Rogério de Oliveira (2008), Vanessa Chiari Gonçalves (2013) and Michel Foucault (1984, 1987). Accepting that literature is intrinsically linked to social phenomena, we intend to investigate how institutional violence is represented in the novel-reportage, what is its conceptual design, as well as its consequences and effects on the mechanisms of social control in Louzeiro's work.
\end{abstract}

Keywords: Institutional Violence; Infância dos Mortos; José Louzeiro.

\title{
Representações da violência institucional em Infância dos Mortos, de José Louzeiro
}

O romance-reportagem Infância dos Mortos (1977) ficcionaliza o processo de marginalização de crianças desamparadas, que perambulam pelas ruas de cidades brasileiras como o Rio de Janeiro, São Paulo e Camanducaia, no sul de Minas Gerais, locais onde o maranhense José Louzeiro (1932-2017) atuou como jornalista a partir de 1950. São episódios de mendicância, prostituição, envolvimento com drogas, furtos $e$ outros atos infracionais cometidos por jovens desamparados, na busca por subsistência, não raro explorados por organizações criminosas e agredidos por agentes de instituições que deveriam amparar, educar e ressocializar esses meninos.

Desde a epígrafe do romancereportagem, retirada do Jornal do Brasil de 05/04/1976, notamos que a narrativa de José Louzeiro estabelece diálogo com obras jornalísticas da época e a preocupação em demonstrar como os índices de violência contra crianças e jovens vulneráveis no Brasil eram altos: "Há cerca de 15 milhões de menores abandonados ou em estado de carência no Brasil ou à espera de alguma ajuda. Representam pouco menos de um terço dos 48.226 .708 brasileiros entre zero e 18 anos", 
estando 42,91\% deles na região sudeste (LOUZEIRO, 1977, p. 8), foco da narrativa em estudo.

Em suas diversas formas, a violência é uma das preocupações mais latentes das sociedades nos últimos séculos. Segundo Minayo (2009, p. 31), os piores índices de "morbimortalidade por violência no Brasil ocorrem nas cidades" e estão ligados à delinquência, acidentes de trânsito e de transporte, ao tráfico de drogas e à difusão das armas de fogo no país. Exemplos dessas variantes da violência são fartos desde as primeiras linhas de Infância dos Mortos (1977), como se pode notar no seguinte impasse vivido pelo protagonista Dito e enfatizado pelo narrador no discurso indireto-livre: "Como agir honestamente com tipos como Cristal (traficante e aliciador), o delegado Mauro, Roxão e Caramelo (policiais truculentos e corruptos na obra)? Apagaram Zebrado, queimaram Pixote, Fumaça e Manguito haviam sumido" (LOUZEIRO, 1977, p. 104). No fragmento, o narrador revela 0 dilema do jovem vulnerável e sua revolta pela falta de opções, que o deixa dividido entre, por um lado, o desejo de agir dentro da lei e de ser aceito socialmente, mas por outro lado a necessidade de sobreviver em meio à violência, à escassez de recursos e à marginalização nas ruas, que vão levando-o cada vez mais a se envolver em situações de conflito com a lei.

No entanto, mesmo que seja frequente, ao falarmos de violência, a ênfase dada à sua variante urbana, onde roubos e mortes adquirem centralidade, pressupõe que em regiões fora do perímetro urbano a violência seja muito menor ou inexistente pode contribuir para uma análise inconsistente do fenômeno. Isso porque mais índices elevados de violência nas cidades podem ser fruto da ênfase maior dada às variantes da violência urbana, inclusive nos veículos de comunicação e outros espaços de debate público, na elaboração das leis e na implementação de políticas de segurança pública. Por outro lado, o inchaço populacional e o crescimento desordenado nas cidades realmente contribuem para a elevação nos números da violência nesses espaços.

Grande parte do romancereportagem de Louzeiro aborda a violência no sudeste brasileiro, em 


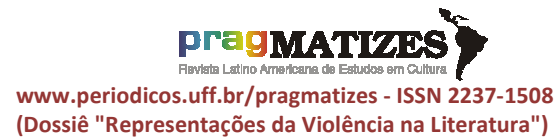

áreas mais urbanizadas do país à época, como Rio de Janeiro e São Paulo, mas também toca na violência ocorrida fora do perímetro urbano e no modo como a violência urbana pode se propagar e afetar outras regiões. Isso se faz através do diálogo com o polêmico caso dos meninos de Camanducaia, no sul de Minas Gerais, ocorrido em outubro de 1974 e investigado por José Louzeiro, inspirando-lhe passagens e personagens de Infância dos Mortos (1977). Em suas investigações sobre o episódio, o jornalista e romancista apurou que quase cem menores de idade recolhidos das ruas $e$ de delegacias, acusados de praticar atos infracionais em São Paulo, tinham sido jogados nus e espancados de uma ribanceira em Camanducaia, por policiais do DEIC, Departamento Estadual de Investigações Criminais de São Paulo. Mas, apesar de o número de jovens e as circunstâncias do evento terem causado escândalo, não se tratava de um caso isolado, como lembra André Gustavo de Paula Eduardo (2013, p. 87).

As dificuldades para publicar textos sobre casos como esse em jornais levam Louzeiro a escrever
Infância dos Mortos (1977) em forma de romance-reportagem, ficcionalizando matérias jornalísticas censuradas pelos órgãos militares e ficcionalizando o contato do escritor com "os arredios garotos encontrados em Camanducaia, notavelmente com Dito, que se torna protagonista" da obra (EDUARDO, 2013, p. 88). Diante do sucesso da narrativa no Brasil e em outros países, o livro ganha uma recriação cinematográfica em 19801981, intitulada Pixote, a lei do mais fraco, e dirigida por Hector Babenco.

Infância dos Mortos (1977) foi concebida durante um dos períodos mais violentos da ditadura militar brasileira, após o chamado golpe dentro do golpe: o Al-5 (1968). Este ato institucional ampliou sobremaneira os mecanismos de repressão e censura do regime, desviando-se dos ideais constitucionalistas liberais, como lembra o professor Marcos Napolitano (2011, p. 217), e inaugurando o que Elio Gaspari (2002) chama de "ditadura escancarada" ou anos de chumbo (1968-1974), com prisões arbitrárias, práticas de tortura e execução de presos. Nesse contexto, foi relevante o "papel da legislação na repressão política, nas escalas de 
violência legal e para-legal, implicando em variadas formas de controle e repressão sobre os diversos atores sociais e políticos" (NAPOLITANO, 2011, p. 216). Surgem também, nesse cenário, os porões do regime que mesmo não sendo "espaços desregrados, virtualmente incontroláveis e autônomos" evidenciam as relações entre autoritarismo institucional e repressão violenta no regime militar brasileiro, o qual valeu-se da "tortura como sistema e não só como mero desvio patológico de alguns indivíduos a serviço do poder", como lembra Napolitano (2011, p. 216).

Vários episódios em Infância dos Mortos (1977) remetem a esses porões do regime, à violência legal e para-legal, à corrupção e aos excessos cometidos por grupos militares e civis, dentro e fora de órgãos públicos, não apenas contra presos políticos, mas também contra presos comuns e até contra crianças e jovens em situação de vulnerabilidade ou autores de atos infracionais. É o que se nota no trecho a seguir do romance-reportagem, em que Manguito, Dito e Fumaça são presos e torturados em uma delegacia de São
Paulo, depois de serem flagrados entregando drogas a uma receptadora no estabelecimento indicado pelo traficante aliciador Cristal. Mas, são apreendidos apenas os meninos, provavelmente delatados. Os policiais não prendem outros integrantes da quadrilha no ponto de prostituição, tráfico de entorpecentes e outras contravenções - "tudo do grupo", como declara Cristal (LOUZEIRO, 1977 , p. 18) - e não aceitam que os jovens acusem Débora, a receptadora das drogas, 0 que sugere envolvimento dos agentes públicos no esquema criminoso:

Dito não sabia o que fazer. Não conseguia entender se o cara era um tira ou traficante amigo de Débora, querendo passar Cristal para trás. Estava confuso e bastante atordoado, pois cada vez mais o braço era torcido e os cabelos esticados.

- Fala, moleque, antes que me enfureça.

- Entreguei tudo a Débora - disse quase chorando.

- Mentira, cachorro! Não mete a mulher nos teus rolos! (...)

- Leva pro confessionário...

O magricela e o moreno puseram-se a empurrar Dito. Agora, sabiam estar numa delegacia. Exatamente o que Dito temia. (...)

- Acho bom abrirem logo o bico. Dr. Mauro não é de brincadeira. Já tirou o couro de muito cara ruim, quanto mais de vocês (...)

- Prometi porrada e é o que vão ter. (LOUZEIRO, 1977, p. 31-33, grifos nossos) 
No trecho, aparecem espaços reservados à tortura e estratégias para coagir depoimentos, apresentadas como habituais em interrogatórios feitos por esses policiais, que incluem até ameaças de entregar os jovens apreendidos a presos para serem estuprados em celas da delegacia, entre suas estratégias para forçar depoimentos: "quem vai primeiro com a bonequinha sou eu" (LOUZEIRO, 1977, p. 37). Isso mostra não apenas a violência institucionalizada nessas forças militares e a corrupção de agentes públicos, mas também a ineficiência de sistemas de segurança, sobretudo se pensarmos que crianças são encarceradas junto com criminosos adultos de diferentes periculosidades na obra.

Trata-se de um entre os muitos exemplos, em Infância dos Mortos (1977), de graves violações à Declaração Universal dos Direitos Humanos, a qual assegura, desde 1948, em seu artigo V, que "ninguém será submetido à tortura nem a tratamento ou castigo cruel, desumano ou degradante". Desobedecendo esse preceito, os policiais lançam mão da "tortura-prova" que, segundo Vanessa Chiari Gonçalves (2013, p. 275), objetiva não exatamente um castigo, mas busca confissões: "todo tipo de sofrimento físico ou psicológico infligido a alguém com o fim de obter informação, declaração ou confissão da vítima ou de terceira pessoa, mediante o emprego de violência física ou grave ameaça”. É exatamente o que se nota no fragmento anterior do romance-reportagem, a "tortura-prova" como uma prática habitual, já que há um cômodo chamado de "confessionário" na delegacia, onde o delegado "já tirou o couro de muito cara ruim" para os torturados "abrirem o bico" (LOUZEIRO, 1977, p. 32-33).

A tortura praticada nessa delegacia e em várias instituições de Infância dos Mortos (1977) lembra o antigo suplício de que nos fala Michel Foucault em obras como Vigiar $e$ Punir: o nascimento da prisão (1987, p. $14,37,65,94)$ : "rito que dava fecho ao crime e mantinha com ele afinidades espúrias", imposição de vergonha e dor para submeter vítimas ao poder, "ritual organizado para marcação das vítimas e manifestação do poder que pune". Entretanto, enquanto o suplício já era considerado em grande parte do mundo ocidental como intolerável, por revelar o 
autoritarismo, a busca de vingança, o cruel prazer de punir (FOUCAULT, 1987, p. 14, 37, 65, 94), ainda é largamente empregado por agentes públicos em várias instituições no romance-reportagem de José Louzeiro. Vários sistemas penais e penitenciários ocidentais já passavam por reformas desde o século XVIII, buscando "punir de outro modo: eliminar essa confrontação física entre carrasco e supliciado" (FOUCAULT, 1987, p. 94, 98), até para atender a interesses capitalistas industriais, que demandam corpos saudáveis para o trabalho e a produtividade. Mas, ao contrário disso, no romancereportagem de Louzeiro (1977), muitas vezes nem um julgamento justo é garantido a vários acusados, incluindo crianças.

Nesse contexto de violência institucional, as práticas violentas são agravadas pelo fato de serem cometidas pela parte que, em tese, deveria garantir a assertividade dos direitos inerentes a toda pessoa. Entretanto, tendo abrangência mais ampla do que outras tipologias de violência, a violência institucional pode ocorrer por ação ou omissão. No excerto do romance-reportagem anteriormente citado, fica mais flagrante a ação institucional violenta contra os meninos em situação de vulnerabilidade, na forma da tortura praticada pelos policiais aos jovens aliciados pelo traficante. Mas, essas ações de grave violação aos direitos dos jovens são acompanhadas de omissões a outros direitos deles, como os direitos de defesa e proteção também já garantidos, desde 1948, pela Declaração Universal dos Direitos Humanos, em seus artigos VIII ao XI, mesmo antes da Constituição Cidadã de 1988 e antes da Lei brasileira número 8.069 - conhecida como ECA: Estatuto da Criança e do Adolescente, de 13 de julho de 1990 dirigir especial atenção aos direitos dos jovens. O Artigo XI da Declaração Universal dos Direitos Humanos, por exemplo, já garantia que "todo ser humano acusado de um ato delituoso tem o direito de ser presumido inocente até que a sua culpabilidade tenha sido provada de acordo com a lei, em julgamento público no qual the tenham sido asseguradas todas as garantias necessárias à sua defesa", no entanto os meninos já sofrem sanções antes do julgamento legal em Infância dos Mortos (1977). 
Para o pesquisador da área de Direito Márcio Rogério de Oliveira (2008), a violência institucional se define como "aquela praticada por organizações da sociedade civil e pelo próprio Estado, por ação ou omissão, contra determinadas minorias ou grupos sociais em situação de vulnerabilidade" (OLIVEIRA, 2008, p. 27). Mas, além da violência institucional que resulta da negligência ou da negação dos serviços, para o autor,

[...] há, evidentemente, a violência institucional que resulta de decisões políticas ou ações concretas dos agentes do Estado, não raro em detrimento de pessoas que este deveria cuidar e proteger, de que são exemplos inapeláveis - mas não únicos - a violência policial e a violência praticada por outros agentes do sistema de segurança pública (OLIVEIRA, 2008, p. 27, grifos nossos).

É possível, então, entender a violência institucional não só como aquela que ocorre relacionada com uma atuação ou omissão do Estado, mas também como aquela que ocorre a partir de decisões, posturas e ações efetivamente adotadas por agentes a serviço do Estado, inclusive por meio de outras modalidades de violência, como a física e a psicológica. Exemplos disso ocorrem nas já mencionadas cenas de tortura aos jovens na delegacia do Dr. Mauro, no romance-reportagem, mas também em casos como o do assassinato e ocultação do cadáver de Pixote pelos seguranças do cemitério, que também podem ser considerados como desdobramentos de violência institucional, já que praticados numa organização social por "outros agentes do sistema de segurança pública" (OLIVEIRA, 2008, p. 27), ainda que não regulamentados ou não fiscalizados adequadamente ou não punidos pelo Estado. Sendo assim, de certo modo, também resultam de omissões do Estado ou de seus agentes, trazendo graves prejuízos a cidadãos que 0 Estado deveria proteger, como se nota no trecho a seguir:

Poucas vezes se sentira assim, encurralado, sem oportunidade de escapar. E se o funcionário fosse na verdade um guarda de segurança? Esperaria que escalassem o muro, a fim de ter um alvo melhor. (...) Se o cara do boné saísse da toca, teria condição de acertá-lo com uma pedra.

(...) Pixote corre, agachando-se e, depois, livremente. Já está perto do muro e nem sombra do homem do boné. Todavia, ouvem-se dois disparos secos.

Pixote cambaleia. Cai. (...) Dito está com pedras nas mãos, sem saber em quem jogá-las.

- Atiraram em Pixote! - diz Fumaça, alarmado. (...) 
Os três saem correndo, agachandose o mais que podem. Outros tiros são disparados, mas ninguém está ferido, Dito chega perto de Pixote. Ele tem os olhos abertos, filetes de sangue a escorrerem do pescoço. A mão amarela se abriu, com as flores murchas que ia levando para Estrelado. Manguito e Fumaça já escalaram o muro. Dito ergue-se, lança as pedras sem saber ao certo o que pretendia atingir. Compreendendo a inutilidade de seu gesto e a impossibilidade de tirar Pixote dali, corre para o muro, salta (LOUZEIRO, 1977, p. 14-15, grifos nossos).

A truculência na ação do segurança do cemitério contrasta com as intenções do jovem Pixote assassinado: levar flores para o túmulo do amigo Estrelado - menino vítima anterior da violência - e atravessar o cemitério para chegar mais rápido ao traficante do outro lado.

Apesar de dividirmos as formas de violência para melhor estudá-las, na prática elas aparecem imbricadas, evidentemente, como vimos ocorrer nos exemplos de Infância dos Mortos (1977) até aqui analisados, em que violência física, psicológica, social, delinquencial e institucional podem se agregar e se agravar. É o que ocorre na delegacia, onde a violência física é acompanhada de tortura psicológica, compondo elementos da violência policial e da institucional, conjuntos de práticas contra os jovens em conflito com a lei. Aliás, esses jovens praticam atos infracionais - violência delinquencial, "na qual as crianças são vítimas e atores" - por vezes para sobreviver a situações de vulnerabilidade, que são desdobramentos de uma violência estrutural "cujas expressões mais fortes são o trabalho infantil, a existência de crianças vivendo nas ruas e em instituições fechadas; e de uma violência social, cujas mais vivas expressões se configuram na violência doméstica" (MINAYO, 2001, p. 91). Abordagens a essas formas de violência contra as crianças no romance-reportagem são notadas até nos apelidos de alguns meninos, como Castigo de Mãe, ou quando meninos relatam violências domésticas como causas de alguns terem fugido de casa para as ruas, ou na primeira cena da narrativa, quando Pixote, menino de apenas onze anos, dentre os quais três vividos na delinquência, dorme nas ruas e precisa enfrentar a violência policial e a criminal, a fome e toda sorte de adversidades:

A manhã estava clara e leve. Pixote livrou-se das folhas de jornal, olhou 0 dia que principiava, os que entravam e saíam apressados na estação de trens. Ergueu-se, antes que os guardas aparecessem. Surgiam por volta de 6 horas e espancavam os 
que podiam pegar. Era a quarta vez que dormia na estação e escapava dos guardas (LOUZEIRO, 1981, p. 9).

Nessa cena, apesar de a ação dos guardas traduzir a violência de maneira mais ostensiva, sobretudo pela sugestão de que tal conduta é frequente, chama atenção também a condição de abandono em que a criança se encontra, violência primeira que desencadeia e viabiliza várias outras violências na obra, de modo escalar.

Percebemos que a noção do termo violência - ao menos no seu uso comum na contemporaneidade, em várias mídias e outros espaços de debate público - pode ser relativizada ou mesmo esvaziada de muitos de seus sentidos, ao se priorizar, a violência física e a criminal comumente. Com isso, ocultam-se inúmeras modalidades tão graves quanto essas ou até mais graves e mais complexas, o que favorece a invisibilidade de muitas omissões e ações violentas que estruturam as sociedades. Sobre isso, Chauí (1999) defende que os fenômenos da violência não se dão de maneira desarticulada na organização social e que existem dispositivos responsáveis por invisibilizar a violência real, assim enumerados:

1- um dispositivo jurídico, que localiza a violência apenas no crime contra a propriedade e contra a vida; 2) um dispositivo sociológico, que considera a violência um momento de anomia social, isto é, como um momento no qual grupos sociais 'atrasados' ou 'arcaicos' entram em contato com grupos 'modernos', e 'desadaptados; 3) um dispositivo de exclusão, isto é, a distinção entre um 'nós brasileiros não-violentos' e um 'eles violentos'; 4) um dispositivo de distinção entre o essencial e o acidental: por essência, a sociedade brasileira não seria violenta, e, portanto, a violência é apenas um acidente na superfície social sem tocar em seu fundo essencial não-violento - eis por que os meios de comunicação se referem à violência com as palavras "surto", "onda", "epidemia", "crise", isto é, termos que indicam algo passageiro e acidental (CHAUÍ, 1999, p. 3, grifos nossos).

No romance-reportagem de Louzeiro, a sociedade dá destaque e punição rigorosa à violência praticada pelos jovens em situação de vulnerabilidade, mas não ao abandono do vulnerável, violência anterior (sofrida cotidianamente pelo inimputável) que, muitas vezes, dá causa ao ato infracional do jovem. Minimiza-se, naturaliza-se ou justificase a parcela de violência estrutural ou institucional e pune-se com rigor (não raro fora da lei) infrações praticadas por grupos excluídos, numa perspectiva bastante patrimonialista do 
que seria direito, em seu sentido mais amplo, que defende os interesses econômicos e materiais das classes altas e médias.

Nessa perspectiva, Minayo (2009), ao conceituar a violência institucional, ressalta elementos relevantes dessa modalidade:

aquela que se realiza dentro das instituições, sobretudo por meio de suas regras, normas de funcionamento e relações burocráticas e políticas, reproduzindo as estruturas sociais injustas. Uma dessas modalidades de violência ocorre na forma como são oferecidos, negados ou negligenciados os serviços públicos (MINAYO, 2009, p. 33).

A violência institucional, então, mais do que produzir ou manter as desigualdades e estruturas sociais injustas, arraiga-se às instituições de maneira circunscrita. Frequentemente a obra Infância dos Mortos (1977) narra episódios de violência em delegacias, celas e até em espaços teoricamente destinados à recuperação ou à socioeducação dos meninos que, como já vimos, à revelia de suas funções institucionais originais, operam como depósito de crianças e jovens. Isso pode ocorrer porque a instituição falha na execução de sua missão original ou porque essa missão é ou tornou-se mera fachada.
Assim, tais instituições reproduzem as estruturas sociais injustas em suas práticas de funcionamento e em suas relações burocráticas e políticas, negando ou negligenciando os serviços públicos básicos (que foram criadas para oferecer) aos jovens, os quais ficam no romance-reportagem sem garantia de seus direitos fundamentais e sociais, sem alimentação, sem escola, sem segurança e sem moradia digna.

O Estado e seus agentes não atuam de forma positiva, no sentido de garantir dignidade e igualdade aos cidadãos, ao contrário perpetuam a desigualdade, como na cena em que Dito, depois de sucessivas capturas e fugas de diversas instituições, acorda algemado a uma cama de enfermaria, em meio a vários garotos agonizando:

Caminhou pela varanda escura, viu o muro, os arames, as lâmpadas fracas. Não poderia fugir facilmente. Teria de atravessar o pátio e, depois, escalar o muro. Um dos guardas aproximava-se. Entrou num dos prédios. Estava todo escuro. Um garoto chorava, outros gemiam. [...] As celas apareceram. Em todas elas havia muitos garotos. A maioria ainda estava caída ao chão. Só uns dois resistiam, magros, olhos fundos. Encostavam-se nas paredes, pernas alongadas, como se não tivessem mais ânimo de levantar-se. Um dos pequenos apenas acompanhava os movimentos de Dito. Mesmo que abrisse a tranca de ferro, não conseguiria mais sair dali. Simplesmente não tinha condição 
de mover-se. Dito se esforçou. Muniu-se de um pedaço de pau e terminou destravando a grade. Puxou o portão que se abriu com ruído. Chegou-se ao garoto. A voz era frágil e lamentosa. - Desde que botaram a gente aqui não nos deram comida. Cada semana vão tirando os que morrem primeiro. Quem tá fazendo isso? - $\mathrm{O}$ inspetor-geral (LOUZEIRO, 1981, p. 101, grifos nossos).

Notamos que essa instituição de acolhimento, supostamente parte de um sistema socioeducativo, que deveria trabalhar pela recuperação da saúde e pela (re)integração social desses jovens, em Infância dos Mortos (1977), mergulha em grave quadro de violência institucional, funcionando como um verdadeiro "morredouro, um lugar onde morrer (...) aliado à função de separação dos indivíduos ditos perigosos para a saúde geral da população", de que nos fala Foucault, em Microfísica do poder (1984, p. 59).

Nesse caso, a tortura institucionalizada, observada no fragmento anterior do romancereportagem, tem objetivos e metodologias bem distintos dos notados no episódio da delegacia do Dr. Mauro porque, ao invés de visar confissões, essa tortura visa a isolar, castigar e eliminar os jovens. Nessa perspectiva, segundo Gonçalves
(2013, p. 275), é possível categorizar a tortura em dois sentidos, a já mencionada "tortura-prova" e também a "tortura-pena". A primeira, como vimos, entende-se por "todo tipo de sofrimento físico ou psicológico infligido a alguém com o fim de obter informação, declaração ou confissão da vítima ou de terceira pessoa, mediante o emprego de violência física ou grave ameaça". Já a segunda, notada na cena da enfermaria, diferencia-se "em relação à sua intencionalidade que, neste caso, será a de submeter a vítima a um intenso e diferenciado sofrimento físico ou psíquico como forma de aplicação de um castigo" (GONÇALVES, 2013, p. 275).

Além dos inúmeros episódios em que predomina a "tortura-prova" na obra, há também várias passagens em que encontramos a "tortura-pena", como quando os meninos são submetidos a uma espécie de veredicto final: recolhidos, no meio da noite, por policiais e levados rumo a um lugar desconhecido por um camburão, depois por um ônibus com janelas cobertas, sempre vigiados por policiais e cães de guarda:

A considerar pelo barulho do motor, o ônibus subia uma estrada de 
ladeira. [...] Os solavancos se prolongaram por uma boa meia hora, até que o sistema de freio foi acionado.

- Agora, cambada, vamos tirando a roupa. Pra onde vão não precisam de nada.

Um dos garotos tentou escapar, foi seguro pelos policiais que começaram a espancá-lo. [...] Em meio ao tumulto os primeiros garotos rolaram pela porta. [...] Dito não conseguia mais saber 0 que se passava [...], quando um cão mordeu-o nas pernas e o policial segurou-o pelo pescoço e começou a puxá-lo, até a porta. Ali, empurrouo com o pé e ele sentiu o espaço faltar aos seus pés. A noite era escura, os primeiros matos que passaram pelo seu corpo e por seu rosto, numa velocidade de vertigem, pareciam-lhe frios, à proporção em que se distanciava, perdia-se como se mais uma vez estivesse caindo num mergulho e procurasse as profundezas do rio, impossível de alcançar (LOUZEIRO, 1981, p. 169171).

O medo, a impotência, a incerteza e a dor dos meninos no fragmento anterior contrasta com a indiferença, o poder e a raiva ou a descontração com que esses agentes do Estado tutelam a "tortura-pena" no romance-reportagem, por vezes rindo, enquanto agridem, ameaçam e condenam sem julgamento legal ou executam sem sentença judicial esses jovens personagens. Trata-se de uma instituição, através de seus agentes representantes, não apenas negando aos cidadãos os serviços e direitos que deveria Ihes garantir, mas eliminando as causas primeiras de sua existência: o seu próprio público-alvo.

Assim, muitas instituições no romance-reportagem funcionam como clínicas de vigiar e punir, cumprindo funções de condenar, isolar, torturar, humilhar ou eliminar marginalizados, por isso são tão temidas pelos jovens em situação de vulnerabilidade. E por isso chegam a ser mesmo comparadas ao cemitério por Pixote, pouco antes de ser assassinado: "Chegou a imaginar que os portões e os muros (do cemitério) servissem para as almas não fugirem, como nas prisões e no internato onde estivera seis meses" (LOUZEIRO, 1977, p. 11). Por isso os jovens se sentem tratados como lixo, tal qual Pixote ao tentar encontrar o túmulo do amigo Estrelado: "Se era por ali que haviam enterrado o pobre Estrelado, então ele tinha sido praticamente jogado fora" (LOUZEIRO, 1977 , p. 13). E é o que pensam os próprios seguranças e o administrador do cemitério sobre o corpo de Pixote, por eles assassinado, como enfatiza o narrador louzeiriano: "Dr. Alencar não está preocupado com a morte do menino, preocupa-o a forma de livrarse do corpo, sem que haja problema" 
(LOUZEIRO, 1977, p. 16-17). Desse modo, muitas instituições no romancereportagem deixam de cumprir suas funções sociais originais e passam a atender a interesses de determinados indivíduos ou grupos no poder, que se impõem através de práticas violentas, muitas vezes, e promovem severas transformações nas culturas institucionais das organizações em questão.

Com tudo isso, o narrador de Infância dos Mortos (1977) encena vários modos de demonstrar como "a perversidade ainda é uma maneira de ser privilegiado", parafraseando Foucault (1987, p. 84). E valoriza a reescrita estética de delitos, atos infracionais, corrupção e várias mazelas sociais, em favor do exercício do pensamento crítico a respeito da perversidade e da violência escalar, da exclusão social e da banalização da morte nesse romance-reportagem, entre outros temas: "Não tinha dúvida quanto ao futuro. Mais cedo ou mais tarde 0 acertariam" (LOUZEIRO, 1977, p. 80).

Deste modo, percebemos que obras literárias como Infância dos Mortos (1977) assumem relevante papel social, pois a literatura, mesmo sem ser uma área científica que faça de seu objeto exclusivo 0 comportamento e as sociedades humanas, contribui de modo relevante no estudo destes. É justamente por apreender a dinâmica social, que a literatura pode assumir funções diante da sociedade, uma delas denominada por Candido (2002) de "função social da literatura". A partir dessa função, é possível analisar obras literárias, tal qual Infância dos Mortos (1977), como fontes pertinentes na busca de compreensão dos fenômenos sociais e, através de seu estudo, pontuar as relações mantidas entre o homem, a literatura e o corte temporal de que são contemporâneos, assim considerando seu valor simbólico, subjetivo e também histórico. Além disso, através da sua carga subjetiva, o texto literário proporciona uma reflexão que suplanta o pragmatismo dos diálogos cotidianos, ressignificando-os, como lembra Schøllhammer (2005): "A literatura que expressa a violência modifica-a sempre que reencena os limites de sua possibilidade. [...] Comunicar a violência é uma maneira não de divulgar a violência, mas de ressimbolizá-la e de reverbalizá-la" 
(SCHØLLHAMMER, 2013, p.128-129).

Essas tarefas relevantes para o estudo da violência no âmbito artístico podem também contribuir para os estudos da violência na sociedade.

\section{Referências bibliográficas}

CANDIDO, Antonio. Textos de intervenção. São Paulo: Ed. Duas Cidades, 2002.

CHAUÍ, M. Uma Ideologia Perversa. Folha de São Paulo, São Paulo, Caderno Mais!, p. 3, 14 de março de 1999.

DECLARAÇÃO UNIVERSAL DOS DIREITOS HUMANOS. Assembleia Geral das Nações Unidas em Paris. 10 dez. 1948. Disponível em: https://nacoesunidas.org/wpcontent/uploads/2018/10/DUDH.pdf. Acesso: 10 dez. 2019.

DUBET, François. Sobre a violência e os jovens. Cadernos de Ciências Humanas - Especiaria, Santa Catarina: UESC, v.9, n.15., p.11-31, 2006. Disponível em: http://www.uesc.br/revistas/especiarias led15/15_1_sobre_a_violencia_e_os_j ovens.pdf. Acesso: 30 jan. $201 \overline{9}$.

EDUARDO, André Gustavo de Paula. José Louzeiro, do romancereportagem ao cinema: estudo da adaptação literária para o audiovisual a partir de Lúcio Flávio e Infância dos Mortos. Dissertação (Mestrado) Universidade Estadual Paulista, Bauru, 2013.

FOUCAULT, Michel. Microfísica do poder. Rio de Janeiro: Graal, 1984.

FOUCAULT, Michel. Vigiar e Punir: 0 nascimento da prisão. Petrópolis, RJ: Vozes, 1987.
GASPARI, Elio. A Ditadura Derrotada. O Sacerdote e o Feiticeiro. São Paulo: Cia da Letras, 2003.

GASPARI, Elio. A Ditadura Encurralada. $O$ Sacerdote $e$ o Feiticeiro. São Paulo: Cia das Letras, 2004.

GASPARI, Elio. A Ditadura Envergonhada. As llusões Armadas. São Paulo: Cia das Letras, 2002a.

GASPARI, Elio. A Ditadura Escancarada. As llusões Armadas. São Paulo: Cia da Letras, 2002b.

GONÇALVES, Vanessa Chiari. Rediscutindo a definição do delito de tortura e sua relação com o crime de maus-tratos. In: SANTIAGO, N. E. A. et alli. Direito penal e criminologia. Florianópolis: FUNJAB, 2013.

LOUZEIRO, José. Biografia entrevista - José Louzeiro. Entrevista a Estranho Encontro. Disponível em: http://estranhoencontro.blogspot.com/2 006/05/biografia-entrevista-joslouzeiro.html. Acesso: 30 jan. 2019.

LOUZEIRO, José. Infância dos Mortos. São Paulo: Círculo do Livro, 1977.

LOUZEIRO, José. Literatura comentada / entrevista biográfica por Antônio Roberto Espinosa. São Paulo: Abril Cultural, 1982.

MINAYO, Maria Cecília de Souza. Conceitos, teorias e tipologias de violências. In: NJAINE, K.; ASSIS, S. G.; CONSTANTINO, P. (orgs.). Impactos da Violência sobre a Saúde. Rio de Janeiro: Editora Fiocruz, 2009.

MINAYO, Maria Cecília de Souza. Violência contra crianças e adolescentes: questão social, questão de saúde. Revista Brasileira de Saúde Materno Infantil, Recife, vol. 1, № 2, p. 91-102, 2001.

NAPOLITANO, Marcos. O golpe de 
1964 e o regime militar brasileiro: apontamentos para uma revisão histórica. Contemporânea, Historia y problemas del siglo $\mathrm{XX}$, Uruguai, vol. 2, ano 2, p. 209-217, 2011.

OLIVEIRA, Márcio Rogério de. Violência Institucional no Sistema Socioeducativo: Quem se Importa? In: FÓRUM PERMANENTE do Sistema de Atendimento Socioeducativo de Belo Horizonte (org.). Desafios da socioeducação: responsabilização e integração social de adolescentes autores de atos infracionais. Belo Horizonte: CEAF, 2008.

SCHØLLHAMMER, Karl Erik. A cena do crime: violência e realismo no Brasil contemporâneo. Rio de Janeiro: Civilização Brasileira, 2013. 